\title{
Cytotoxic, Anti-Proliferative and Apoptotic Effects of Tribulus terrestris L. Fruit Extract on Human Prostate Cancer Lncap and Colon Cancer HT-29 Cell Lines
}

\author{
Masoud Pourali, ${ }^{1}$ Mohammad Mehdi Yaghoobi, ${ }^{2,}$ and Mohammad Hosein Salehi Sormaghi ${ }^{3}$ \\ ${ }^{1}$ Department of Biotechnology, Graduate University of Advanced Technology, Kerman, Iran \\ ${ }^{2}$ Department of Biotechnology, Institute of Science and High Technology and Environmental Sciences, Graduate University of Advanced Technology, Kerman, Iran \\ ${ }^{3}$ Department of Pharmacy, Tehran University of Medical Sciences, Tehran, Iran \\ "Corresponding author: Mohammad Mehdi Yaghoobi, Department of Biotechnology, Institute of Science and High Technology and Environmental Sciences, Graduate \\ University of Advanced Technology, End of Haft-Bagh Hwy, Kerman, Iran. Tel: +98-3431623209, Fax: +98-3433778014, E-mail: m.yaghoobi@kgut.ac.ir
}

Received 2015 October 03; Revised 2016 August 25; Accepted 2016 September 14.

\begin{abstract}
Background: The medicinal herb Tribulus terrestris L. (Zygophyllaceae) has been used for a long time to treat various kinds of diseases including hepatocellular carcinoma.

Objectives: The aim of the present study was to investigate the anticancer activity of hydroalcoholic extract of T. terrestris fruit on prostate and colon cancerous cell lines.

Materials and Methods: The activity of the extract was studied at seven different concentrations on three cell lines, human colon adenocarcinoma (HT29), prostate carcinoma (LNCap-FGC-10) and fibroblast-like cells (HSkMC). MTT, bromo-2'-deoxyuridine(BrdU) and terminal deoxynucleotidyl transferase mediated dUTP nick end labeling (TUNEL) assays were used for measuring cytotoxicity, cell proliferation and apoptotic cell death, respectively.

Results: The $\mathrm{IC}_{50}$ index of the extract of $T$. terrestris was obtained as $0.3 \mu \mathrm{g} / \mathrm{mL}, 7.1 \mu \mathrm{g} / \mathrm{mL}$ and $8.7 \mu \mathrm{g} / \mathrm{mL}$ for prostate, colon and fibroblast-like cell lines, respectively. Tribulus terrestris L. was significantly more toxic on prostate cancer cell line than on colon cancer cell and fibroblast-like cells (P value $<1 \%$ ). Quantitating BrdU incorporation at the highest concentration was determined as 0.097 and 0.018 . Furthermore, the extract induced $74 \%$ and $46 \%$ apoptosis in prostate and colon cancer cells, respectively.

Conclusions: These data indicate that $T$. terrestris extract has cytotoxic, anti-proliferative and pro-apoptotic activities. It was less toxic against normal human fibroblast-like cells in comparison to cancer cell lines. Further in vivo research would help explore and interpret the potential properties of $T$. terrestris extract and its components as an anticancer supplement.
\end{abstract}

Keywords: HT-29, LNCap, Antitumor, Cytotoxic, Anti-proliferative, Apoptosis, Tribulus terrestris L.

\section{Background}

Cancer is a major health burden at global level. Prostate cancer is the second most common cancer and the second leading cause of cancer death in American males. Colorectal cancer is also the third most common cancer diagnosed in both males and females and the third leading cause of cancer-related death in the United States (1). Due to the diverse side effects of synthetic drugs, finding novel pharmaceutical sources for replacement has become very crucial. Attention toward medicinal plants has occurred mainly due to promising effects of such plants in preventing or treatment of many diseases. Today, about $70 \%$ of available anti-cancer drugs originate from plants or other natural products (2). Therefore, the nature is still the main source for discovering new drugs, especially anticancer drugs.

Tribulus terrestris L. is a flowering plant of the Zygophyllaceae family and is native to tropical and temperate re- gions. This plant is used in traditional medicine in many countries including India and China. Tribulus terrestris fruits are used to treat edema, abdominal distention and sexual dysfunction. It has anti-inflammatory, anticancer, antibacterial, and anticariogenic activities (3). This medicinal plant produces high levels of flavonoids, flavonol glycosides, steroidal saponins, and alkaloids (3). Tribulus terrestris has a preventive efficacy against Ultraviolet B (UVB)induced carcinogenesis by scavenging free radicals and is capable of protecting cells against chemical and oxidative damage (4). The cytostatic effects of saponin against malignant cells and its anticancer properties have been studied $(5,6)$. The plant extract containing this substance has less toxicity for normal human skin fibroblasts compared to various types of cancer cells (7).

Kim et al. reported that aqueous extract of $T$. terrestris blocks proliferation and induces apoptosis in human liver cancer cells HepG2 (8). The current study aimed to investigate the cytotoxic, anti-proliferative and apoptotic effect of 
hydro-alcoholic extract of $T$. terrestris plant fruit on human prostate and colon cancer cell lines.

\section{Methods}

\subsection{Plant Sample Collection and Extraction}

The T. terrestris plant fruits were collected in the second half of July from the foothills overlooking the city of Damavand, Iran, located at $35.720 \mathrm{~N}$ and $52.068 \mathrm{E}$ (altitude 1941 $\mathrm{m})$. The specimens were transferred to the department of pharmacognosy of the Tehran University of Medical Sciences and confirmed by a herbarium specialist. The No of the deposited sample in the herbarium was PMP 645. The fruits were washed with distilled water and dried in dim light for a week. Then, they were milled and extraction was performed from the resulting powder by Soxhlet extractor, according to the routine procedure using a solvent composed of $20 \%$ distilled water and $80 \%$ methanol. Extracts were kept in enclosed containers and stored in the refrigerator at $4^{\circ} \mathrm{C}$ until the time of tests.

\subsection{Cell Culture}

Human colon adenocarcinoma cell line (HT29), prostate carcinoma cell line (LNCap-FGC-10) and fibroblastlike cells derived from human muscle (HSkMC) were purchased from the national cell bank of the Pasteur institute of Iran. They were cultured in RPMI1640 medium with $10 \%$ fetal bovine serum (FBS) (Invitrogen, USA), and were incubated in a $37^{\circ} \mathrm{C}$ incubator containing $5 \% \mathrm{CO}_{2}$. The cell viability was determined by $0.4 \%$ Trypan blue staining.

\subsection{Assessment the Extract Cytotoxicity Using the MTT Assay}

The MTT cell proliferation kit (Roche Applied Science, Germany) was used for measurement of cytotoxicity rate as recommended by the manufacturer. Based on previous studies, $0.6 \mu \mathrm{g} / \mathrm{mL}$ and $1.3 \mu \mathrm{g} / \mathrm{mL}$ of 5-Fluorouracil (5$\mathrm{Fu}$ ) as positive controls for prostate and colon cancer cell lines were used, respectively. The extract was dissolved in RPMI1640 medium in eight concentrations of $0,0.5$, $1,2,5,7,10$ and $12 \mu \mathrm{g} / \mathrm{mL}$. The three cell lines were cultured in $50 \mu \mathrm{L}$ medium with cell density of 5000 cells per well in quadruplicate rows in 96-well plate for 24 and 48 hours at $37^{\circ} \mathrm{C}$. Then, $5 \mu \mathrm{L}$ of each of the eight concentrations, as well as 5-Fu were added to the wells in eight columns. After 24 hours, $5 \mu \mathrm{L}$ MTT labeling reagent (5 $\mathrm{mg} / \mathrm{mL}$ ) was added to each well. After four hours the culture medium was replaced with $50 \mu \mathrm{L}$ of fresh medium, and $50 \mu \mathrm{L}$ solubilization solution $(10 \%$ SDS in $0.01 \mathrm{M} \mathrm{HCl})$ was added to each well. The next day, absorbance of the wells was measured at 490 and 680 nm, using Biotek Enzyme linked-immunosorbent assay (ELISA) reader (Cedex,
France). The viability percentage was calculated from the following equation: percentage of viable cells $=$ (Treated cells absorbance / control cells absorbance) $\times 100$. The $\mathrm{IC}_{50}$ values were calculated for all of the extracts by ED50 plus V1.0 software.

\subsection{Measurement of Cell Proliferation Rate Using BrdU Con- sumption Assay}

The inhibitory effects of the extracts on DNA synthesis and cell proliferation was measured by cell proliferation ELISA, bromo-2'-deoxyuridine (BrdU) kit (Roche Applied Science, Germany), as recommended by the manufacturer. In this test, the three mentioned cell lines were cultured in 96-well plates in a final volume of $50 \mu \mathrm{L}$ medium and treated with the same mentioned concentrations of $T$. terrestris plant for 24 hours at $37^{\circ} \mathrm{C}$. Then, $5 \mu \mathrm{L}$ BrdU labeling solution $(100 \mu \mathrm{M})$ was added and re-incubated for three hours at $37^{\circ} \mathrm{C}$. Then, the labeling medium was removed and $200 \mu \mathrm{L} /$ well FixDenat solution was added and incubated for 30 minutes at room temperature. Next, FixDenat solution was removed thoroughly and incubated in $100 \mu \mathrm{L} /$ well anti-BrdU-POD solution for 90 minutes at room temperature. After removing antibody conjugate and rinsing three times with $200 \mu \mathrm{L} /$ well PBS, $100 \mu \mathrm{L} /$ well substrate solution (TMB) was added to each well for 20 minutes. Finally, the absorbance was measured at $370 \mathrm{~nm}$ and $490 \mathrm{~nm}$ using the Biotek ELISA reader.

2.5. Apoptotic Cell Death Diagnostic Test by the Terminal Deoxynucleotidyl Transferase Mediated dUTP Nick End Labeling (TUNEL) Method

In situ cell death detection terminal deoxynucleotidyl transferase mediated dUTP nick end labeling (TUNEL) kit TMR Red (Roche Applied Science, Germany) was used to identify cell death resulting from addition of the extract, according to the manufacturer's protocol. The prostate and colon cancer cell lines were cultured on sterile cover slip in six-well plates and treated with $7 \mu \mathrm{g} / \mathrm{mL}$ of the extract for 24 hours. Then the slides were fixed for one hour with $4 \%$ paraformaldehyde, permeabilized by $0.1 \%$ Triton $\mathrm{X}-100$ for two minutes and incubated with $50 \mu \mathrm{L} /$ well TUNEL reaction mixture in dark humidified incubator at $37^{\circ} \mathrm{C}$ for one hour. Finally, the cover slips were washed twice with Phosphate Buffered Saline (PBS), dehydrated and mounted. Then the cells were observed under fluorescence microscope (Axioplan 2, Zeiss, Germany) (excitation and detection at 540 and $580 \mathrm{~nm}$, respectively). Five random fields were photographed by Canon PowerShot A620 camera, and the apoptosis percentage was calculated as a percentage of positively stained cells among other cells. 


\subsection{Experimental Design and Statistical Analysis}

In order to assess the cytotoxicity and cell proliferation rate in the presence of extract, the experiments were repeated four times, and the results of MTT and BrdU were estimated as viability percentage and absorption rate, respectively. The analysis of variance (ANOVA) results and mean comparison of data of four replicates were studied using SPSS statistical software. The means of viability percentage by MTT method were compared by the Dunnett's test and the treatments means in measuring cell proliferation rate were compared by Duncan's multiple range test. A P value of $<0.01$ was considered statistically significant.

\section{Results}

\subsection{Evaluation of Cytotoxicity Using the MTT Method}

To assess toxicity of the extract, each of the three cell lines were treated with seven different concentrations of T. terrestris for 24 and 48 hours and the MTT test was performed. Visual observations indicated that viability of cancer cell lines were increasingly reduced while the concentrations of the extract were increased. The cells exhibited some manifestation of cell death particularly at high concentration ( $5 \mu \mathrm{g} / \mathrm{mL}$ and above). The morphology of the cells altered into a spherical shape. Moreover, the nucleus shrunk and became denser and the cell membrane blistered. The cell debris due to cell destruction was clearly visible in culture medium. Morphological changes induced by the extract were more prominent on prostate cancer cell line compared to colon cancer cell line. Such morphological changes were not observed in untreated cells (Figures 1 and 2). Nearly all concentrations of the extract triggered massive cell death after 48 hours of treatment in all cell lines.

The Dunnett's test output indicated that $99 \%$ of the reduction in viability of the prostate cancer cell lines, $97 \%$ of the reduction in viability of the colon cancer cell lines, and $90 \%$ of the reduction in viability of the HSkMC cells were attributable to the T. terrestris extract. The minimum percentages of cell viability in prostate, colon cancer and HSkMC cells were $13.8 \%, 27.9 \%$ and $42.4 \%$ at $12 \mu \mathrm{g} / \mathrm{mL}$ concentration of the extract, respectively.

The $\mathrm{IC}_{50}$ index of the extract of T. terrestris was obtained as $0.3 \mu \mathrm{g} / \mathrm{mL}, 7.1 \mu \mathrm{g} / \mathrm{mL}$ and $8.7 \mu \mathrm{g} / \mathrm{mL}$ for prostate, colon and HSkMC cells, respectively. The extract was significantly more toxic on prostate cancer cell line than colon cancer cell and HSkMC cells. The viability of the prostate cancer cell lines decreased sharply at minimum concentration of $0.5 \mu \mathrm{g} / \mathrm{mL}$ and above $(\mathrm{P}<1 \%)$. However, the extract was not lethal at lower concentrations for colon cancer cells. Therefore, only at concentration of $7 \mu \mathrm{g} / \mathrm{mL}$ and more the toxicity was significant $(\mathrm{P}<1 \%)$ (Figure 3 ).

\subsection{Evaluation of Cell Proliferation Rate Using BrdU Test}

In order to determine whether growth inhibitory effect of T. terrestris extract was due to the inhibition of proliferation, its effect on the rate of cell proliferation was analyzed by measuring BrdU incorporation into DNA in the three cell lines. The cell lines were treated with seven concentrations of the extract for 24 hours, and then the incorporated BrdU was measured. The results showed the proliferation of all cell lines decreased markedly at $1 \mu \mathrm{g} / \mathrm{mL}$ and above $(\mathrm{P}<1 \%)$. However, at lower concentrations (less than $1 \mu \mathrm{g} / \mathrm{mL}$ ) it had no suppressive effect on proliferation of HSkMC cells. The Duncan's test indicated that 93\% of reduction in prostate cancer cell proliferation, $94 \%$ in colon cancer cells and 92\% in HSkMC cells were due to the plant extract. The proliferation of colon cancer cells was most inhibited by $0.5-5 \mu \mathrm{g} / \mathrm{mL}$ concentrations of the extract, while the prostate cells were less inhibited than colon and HSkMC cells $(\mathrm{P}<1 \%)$ (Figure 4$)$.

\subsection{Evaluation of in Situ Cell Death by the TUNEL Assay}

In the last part of the study, the effect of T. terrestris extract on inducing apoptotic death was studied. Prostate and colon cancer cell lines were treated with $7 \mu \mathrm{g} / \mathrm{mL}$ of the extract for 24 hours, and then, the TUNEL test was performed. As shown in Figure 5, both treated cells demonstrated red fluorescence indicative of apoptotic cell death. However, no fluorescence signal was observed in the negative control. The test showed $74 \%$ and $46 \%$ apoptotic cell death in prostate and colon cancer cells, respectively (Figure 5).

\section{Discussion}

The purpose of this study was to evaluate the effect of T. terrestris fruit extract on viability, proliferation and induction of death in two cancer cells and normal fibroblastlike cells. The minimum percentages of cell viability in prostate, colon cancer and HSkMC cells were 13.8\%, 27.9\% and $42.4 \%$ at $12 \mu \mathrm{g} / \mathrm{mL}$ concentration of the extract, respectively. Thus, cytotoxic effects of the extract on fibroblast cells were less than prostate and colon cancer cell lines (Figure 3). This result is consistent with the results of Neychev et al. in which lower toxicity of the plant extract was observed for fibroblast cells in comparison to cancer cells (7). Also, the $\mathrm{IC}_{50}$ index of the extracts indicates more mortality in the prostate cancer cells compared to the two other cells, which indicates the greater sensitivity of prostate cancer cells. More than $90 \%$ of the reduction in proliferation of all of the cells was due to the extract. As the concentration of the extract increased, the DNA synthesis was decreased at a significant level in all three cell lines. 
Figure 1. The Morphological Changes of LNCap-FGC-10 Cells Treated with Tribulus terrestris Extract for 24 Hours
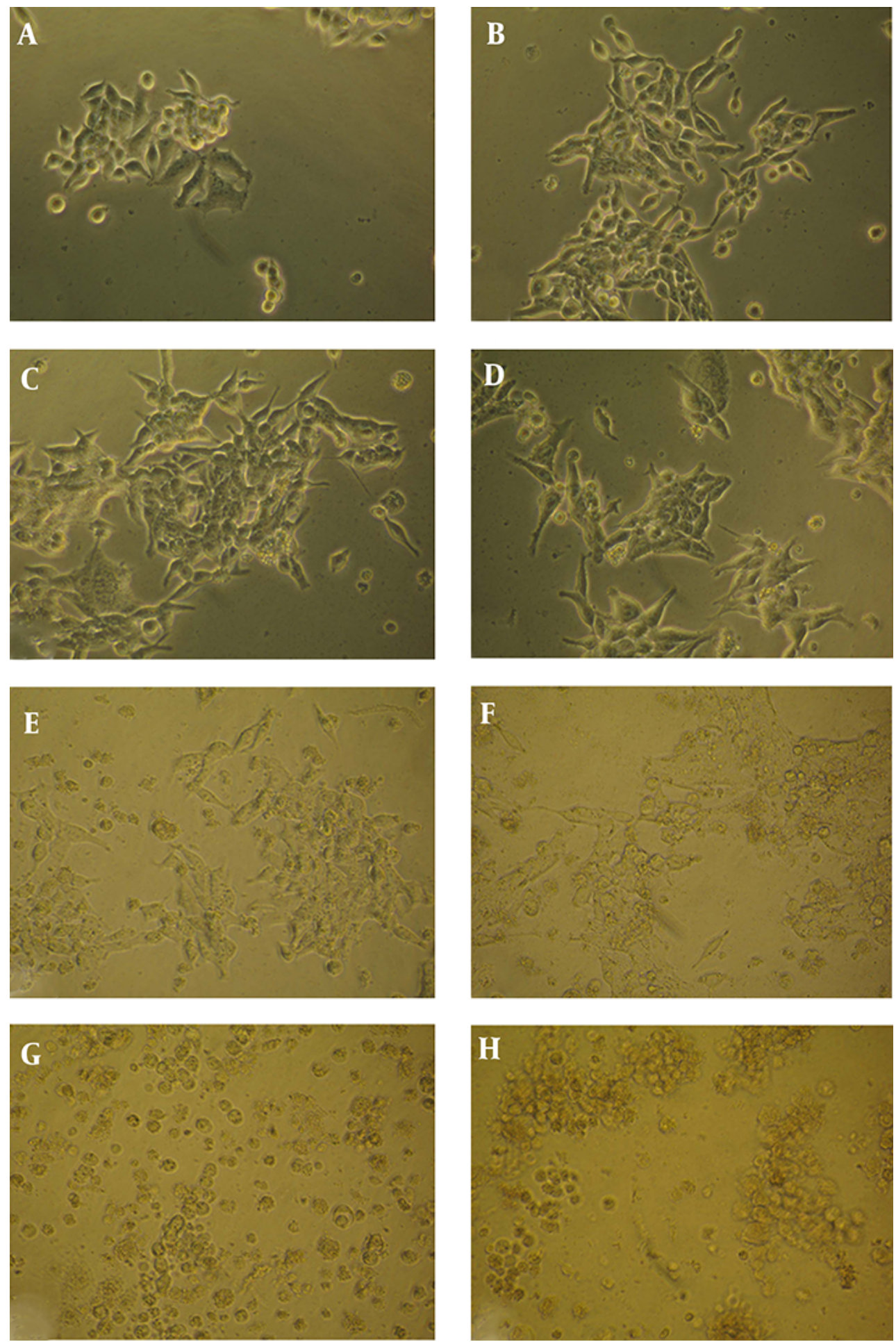

A, negative control $0 \mu \mathrm{g} / \mathrm{mL} ; \mathrm{B}, 0.5 \mu \mathrm{g} / \mathrm{mL} ; \mathrm{C}, 1 \mu \mathrm{g} / \mathrm{mL} ; \mathrm{D}, 2 \mu \mathrm{g} / \mathrm{mL} ; \mathrm{E}, 5 \mu \mathrm{g} / \mathrm{mL} ; \mathrm{F}, 7 \mu \mathrm{g} / \mathrm{mL} ; \mathrm{G}, 10 \mu \mathrm{g} / \mathrm{mL} ; \mathrm{H}, 12 \mu \mathrm{g} / \mathrm{mL}$ 
Figure 2. The Morphological Changes of HT29 Cells Treated with Tribulus terrestris Extract for 24 hours
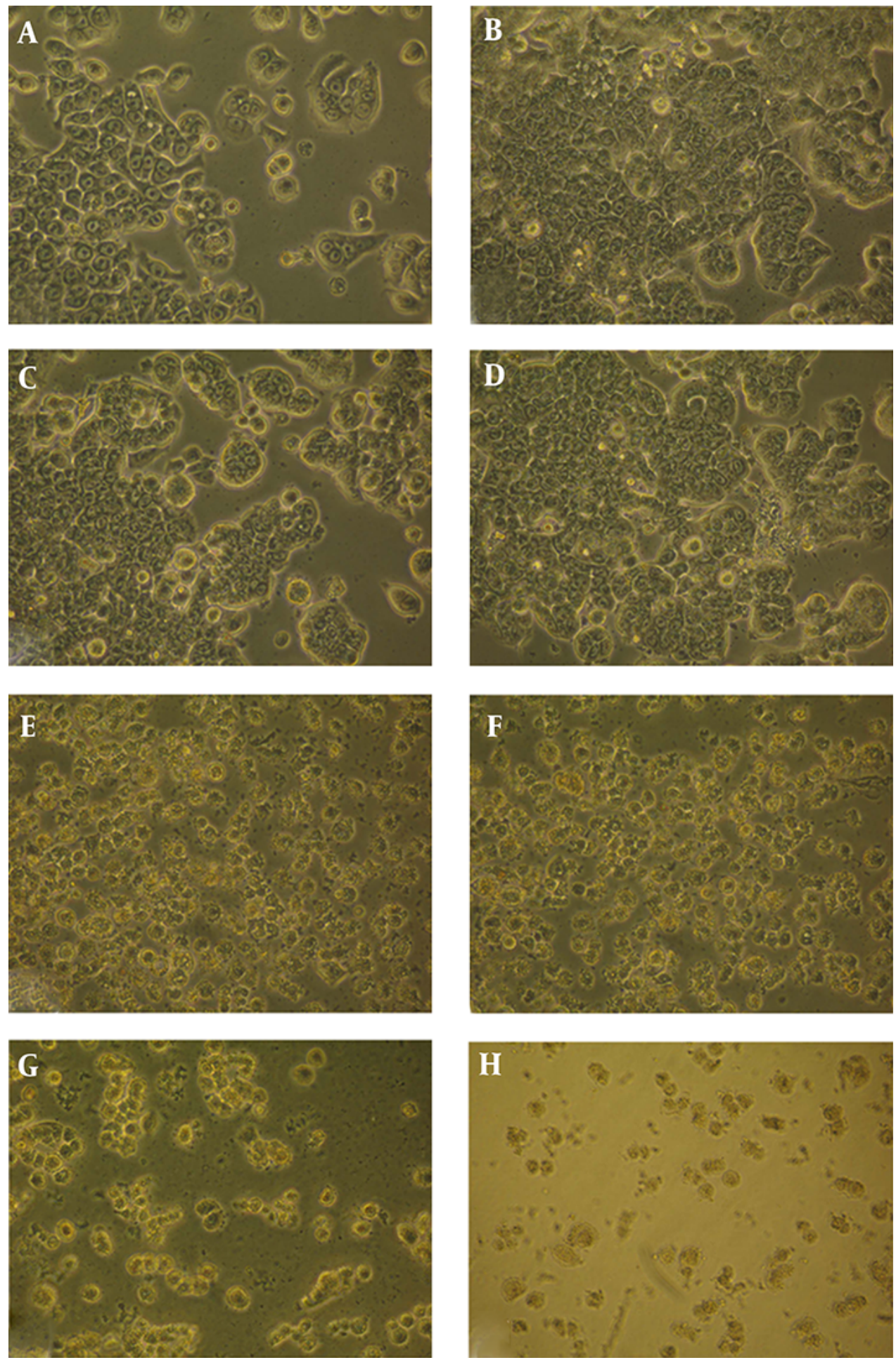

A, Negative control $0 \mu \mathrm{g} / \mathrm{mL} ; \mathrm{B}, 0.5 \mu \mathrm{g} / \mathrm{mL} ; \mathrm{C}, 1 \mu \mathrm{g} / \mathrm{mL} ; \mathrm{D}, 2 \mu \mathrm{g} / \mathrm{mL} ; \mathrm{E}, 5 \mu \mathrm{g} / \mathrm{mL} ; \mathrm{F}, 77 \mu \mathrm{g} / \mathrm{mL} ; \mathrm{G}, 10 \mu \mathrm{g} / \mathrm{mL} ; \mathrm{H}, 12 \mu \mathrm{g} / \mathrm{mL}$. 
Figure 3. The Cytotoxic Effects of Tribulus terrestris Extracts on the LNCap-FGC-10, HSkMC and HT29 cell lines

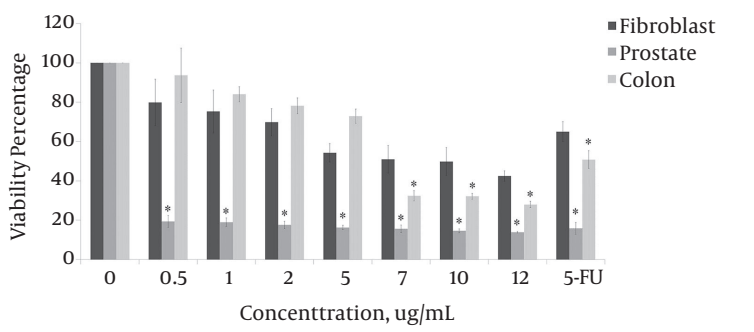

The cells were incubated with seven concentrations of $T$. terrestris extract for 24 hours in MTT test. 5-FU was used as a positive control drug. Data were presented as the mean \pm standard error of independent quadruplicate experiments and analyzed in Duncan's test (*indicates $\mathrm{P}<0.01$ ).

Figure 4. Dose Response Curve of the Tribulus terrestris Extract Effect on LNCap-FGC10, HSkMC and HT29 Cell Proliferation

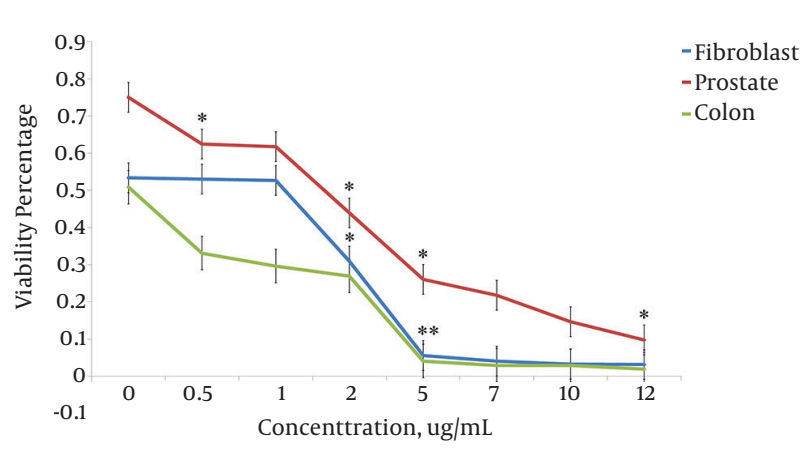

The data were expressed as the absorbance of BrdU incorporation. The cells were incubated with seven concentrations of extracts for 24 hours in the BrdU test. The mean of the groups were compared by Dunnett's test (*indicates $\mathrm{P}<0.01$ ).

This indicates the suppressor effect of the extract on cell proliferation (Figure 4). Similar to this result, Kim et al. reported the lowering effects of aqueous extract of $T$. terrestris plant on liver cancer cell line (8).

Treatment with $7 \mu \mathrm{g} / \mathrm{mL}$ of the extract triggered $74 \%$ and $46 \%$ apoptotic death in prostate and colon cancer cell lines, respectively. Since only specific ligands such as FAS ligand and tumor necrosis factor (TNF) can stimulate external pathway of apoptosis, it is unlikely that components of the extract act through extracellular pathways of apoptosis. However, a wider range of damage including DNA damage and disturbance in mitochondrion membrane can launch the intrinsic pathway of apoptosis. However, internal or external pathways launched by the extract need further studies. Furthermore, to identify which components of the extract induce apoptosis, all of them should firstly be isolated individually by GC-MS or preparative HPLC and then their effects on the cells should be studied. Kim et al. reported that T. terrestris extract could trigger apoptosis in liver cancer cell by preventing the NF- $\kappa$ B factor signaling (8). This finding confirms their observation, however we cannot conclude that inhibition of NF- $\kappa$ B signaling is the sole mechanism involved in apoptosis in our study.

Comparison of $T$. terrestris extract effects on prostate and colon cancer cells indicates higher sensitivity of the prostate cancer cells than the colon cancer cells. This is also demonstrated by the TUNEL test. It is supposed that the effects of the extract are related to the saponin component present in Tribulus terrestris. In the study of Bedir et al., steroidal saponins purified from this plant were used against several cancer cell lines and exhibited a broad range of anticancer activity (5). Molecular mechanisms of saponins include: rapid onset of apoptosis and suppression of cell proliferation, which are related to initial activation of caspase 3, P-ERK1/2 and Dephosphorylation genes $(5,9,10)$.

The result of our study on prostate cancer cells is similar to their result, thus a high power of the extract is evident in all three tests. The prostate cancer cells experienced $74 \%$ apoptosis at $7 \mu \mathrm{g} / \mathrm{mL}$ concentration. Only $15 \%$ of the cells survived during the MTT test at the same concentration. In analysis of BrdU test, the highest rate of DNA synthesis prevention was at $12 \mu \mathrm{g} / \mathrm{mL}$. The tests results regarding colon cancer cell line were also similar and the outputs of three tests were consistent with each other. However, the cytotoxic effects and prevention of DNA synthesis were not significant at less than $5 \mu \mathrm{g} / \mathrm{mL}$. Studying the behavior of colon cancer cells indicates 32\% viability and $46 \%$ apoptosis at $7 \mu \mathrm{g} / \mathrm{mL}$ concentration.

Collectively, our results indicate that colon cancer cells were less sensitive to the plant extract than prostate cancer cells and fibroblast-like cells are more resistant than both cancer cells. However, since our experiments were performed at in vitro conditions, for clinical utilization, it is necessary to further analyze their anticancer effects with in vivo conditions.

\section{Acknowledgments}

This work was supported financially by Grant No. 1.2707 from Institute of Science and high technology and environmental sciences. 


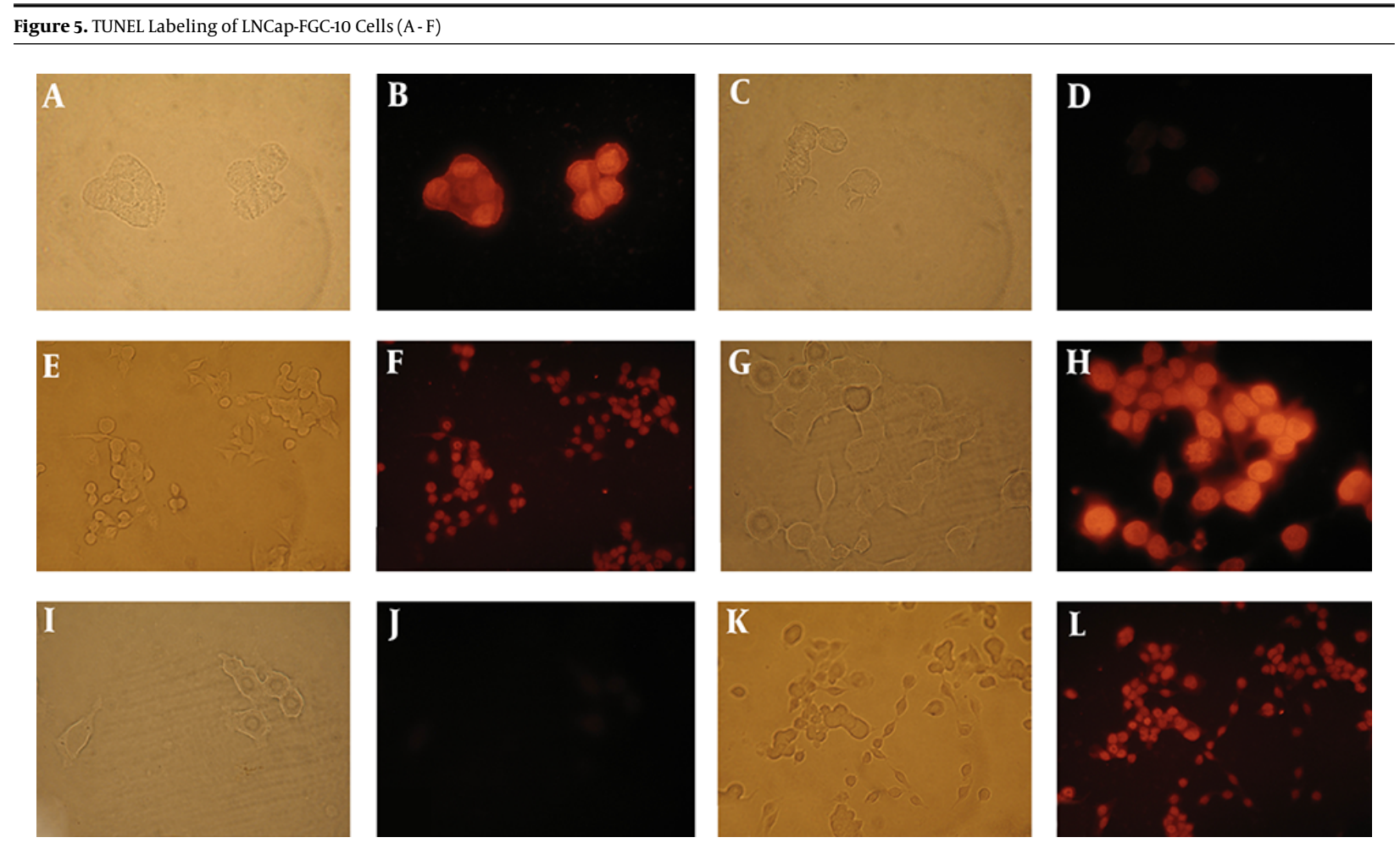

A and B exhibit positive control (all of the nucleuses were stained in DNase I treated cells). C and D negative control (without terminal transferase) no fluorescence was detected in the nucleus. E and F TUNEL labeling of LNCap- FGC-10 cells treated with $7 \mu \mathrm{g} / \mathrm{mL}$ T. terrestris extract for 24 hours. TUNEL labeling of HT29 cells (G-L). G and H exhibited positive control (all of the nucleuses were stained in DNase I treated cells.). I and J negative control (no fluorescence was detected in the nucleus). Kand L TUNEL labeling of HT29 cells treated with $7 \mu \mathrm{g} / \mathrm{mL}$. terrestris extract for 24 hours. The left pictures correspond to the same field, which were taken under light microscope. The same field under fluorescent microscope are on the right.

\section{References}

1. Siegel RL, Miller KD, Jemal A. Cancer statistics, 2015. CA Cancer J Clin. 2015;65(1):5-29. doi:10.3322/caac.21254. [PubMed: 25559415].

2. Newman DJ, Cragg GM. Natural products as sources of new drugs over the 30 years from 1981 to 2010. J Nat Prod. 2012;75(3):311-35. doi: 10.1021/np200906s. [PubMed: 22316239].

3. Chhatre S, Nesari T, Somani G, Kanchan D, Sathaye S. Phytopharmacological overview of Tribulus terrestris. Pharmacogn Rev. 2014;8(15):4551. doi: 10.4103/0973-7847.125530. [PubMed: 24600195].

4. Sisto M, Lisi S, D’Amore M, De Lucro R, Carati D, Castellana D, et al. Saponins from Tribulus terrestris L. protect human keratinocytes from UVB-induced damage.J Photochem Photobiol B. 2012;117:193-201. doi:10.1016/j.jphotobiol.2012.10.002. [PubMed: 23142932].

5. Bedir E, Khan IA, Walker LA. Biologically active steroidal glycosides from Tribulus terrestris. Pharmazie. 2002;57(7):491-3. [PubMed: 12168535].

6. Ivanova A, Serly J, Dinchev D, Ocsovszki I, Kostova I, Molnar J. Screening of some saponins and phenolic components of Tribulus terrestris and Smilax excelsa as MDR modulators. In Vivo. 2009;23(4):545-50. [PubMed: 19567388].

7. Neychev VK, Nikolova E, Zhelev N, Mitev VI. Saponins from Tribulus terrestris L are less toxic for normal human fibroblasts than for many cancer lines: influence on apoptosis and proliferation. Exp Biol Med (Maywood). 2007;232(1):126-33. [PubMed: 17202593].

8. Kim HJ, Kim JC, Min JS, Kim MJ, Kim JA, Kor MH, et al. Aqueous extract of Tribulus terrestris Linn induces cell growth arrest and apoptosis by down-regulating NF-kappaB signaling in liver cancer cells. J Ethnopharmacol. 2011;136(1):197-203. doi: 10.1016/j.jep.2011.04.060. [PubMed: 21549825].

9. Sun B, Qu W, Bai Z. The inhibitory effect of saponins from Tribulus terrestris on Bcap-37 breast cancer cell line in vitro [ in Chinese ]. Zhong Yao Cai. 2003;26(2):104-6. [PubMed: 12795220].

10. Sun B, Qu WJ, Zhang XL, Yang HJ, Zhuang XY, Zhang P. Investigation on inhibitory and apoptosis-inducing effects of saponins from Tribulus terrestris on hepatoma cell line BEL-7402 [ in Chinese ]. Zhongguo Zhong Yao Za Zhi. 2004;29(7):681-4. [PubMed: 15503780]. 